\title{
Regional Review
}

\section{An Algerian perspective on non-typhoidal Salmonella infection}

\author{
Bilal Djeghout ${ }^{1}$, Ammar Ayachi $^{2}$, Bianca Paglietti ${ }^{1}$, Gemma C Langridge $^{3}$, Salvatore Rubino ${ }^{1}$ \\ ${ }^{1}$ Laboratory of Microbiology and Virology, Department of Biomedical Sciences, University of Sassari, Sassari, Italy \\ ${ }^{2}$ Laboratory of Microbiology and Immunology, Institute of Veterinary Science and Agronomic Sciences, University \\ of Batna, Algeria \\ ${ }^{3}$ Medical Microbiology Research Laboratory, Norwich Medical School, University of East Anglia, Norwich, United \\ Kingdom
}

\begin{abstract}
Non-typhoidal Salmonella (NTS) represents a leading cause of food-borne disease worldwide. It is a global public health concern: more than 94 million cases and 115,000 deaths are reported every year, with a disproportionate impact in developing countries. The prevalence of multidrug-resistant (MDR) Salmonella strains is another major health concern which affects antimicrobial treatment, as many studies report that infections caused by MDR strains are more severe than those caused by susceptible strains. In Algeria, NTS represent one of the primary causes of salmonellosis in both humans and food animal production, especially poultry. Epidemiological surveillance systems and monitoring programs for Salmonella infections are essential requirements to provide data useful for the effective detection and control of Salmonella outbreaks. The present review will supply a perspective on NTS infection, pathogenesis and antimicrobial resistance with a focus on the epidemiology of salmonellosis in Algeria.
\end{abstract}

Key words: Algeria; developing countries; multi-drug-resistant; non-typhoidal Salmonella

J Infect Dev Ctries 2017; 11(8):583-590. doi:10.3855/jidc.9456

(Received 26 May 2017 - Accepted 28 July 2017)

Copyright (C) 2017 Djeghout et al. This is an open-access article distributed under the Creative Commons Attribution License, which permits unrestricted use, distribution, and reproduction in any medium, provided the original work is properly cited.

\section{Background}

Salmonella infections are a primary concern for public health worldwide [1]. Salmonella is a Gram negative facultative anaerobe belonging to the Enterobacteriaceae [2]. Salmonella enterica is classified into more than 2500 serotypes based on two antigenic determinants: the somatic $(\mathrm{O})$ antigen, and flagellar (H: phases 1 and 2 ) antigen $[3,4]$ and clinically divided into two groups based upon the disease caused: typhoidal and non-typhoidal salmonellosis. Despite close genetic relatedness, typhoidal and non-typhoidal Salmonella (NTS) provoke different illnesses and a divergent response from the human immune system [5]. The Centers of Disease Control and Prevention (CDC) estimate that globally there are 94 million of cases of non-typhoidal salmonellosis, with 115,000 deaths every year [6]. Infection due to NTS is mainly associated with the consumption of contaminated raw meat, eggs and chicken, milk and other dairy products, fish and other sea foods, fruits and vegetables [7]. Food-borne NTS infection has a significant economic impact in both high- and low-income countries in terms of prevention and surveillance systems [8].
The concern with NTS infection has heightened after the emergence of multidrug-resistant Salmonella strains, as these pathogens are more virulent and responsible for adverse outcomes in infected patients [9]. In Algeria, several outbreaks of salmonellosis have been observed during recent years in both humans and food animal production, particularly poultry [10]. Lapses in hygiene practices are a major cause of foodborne NTS disease in humans, as well as the consumption of contaminated eggs and egg products with Salmonella enterica subspecies enterica serovar Typhimurium (hereafter $S$. Typhimurium) and $S$. Enteritidis [11].

\section{Pathogenesis}

NTS are transmitted by the oral-fecal route via contaminated food and water and are mostly associated with inadequate sanitation and hygiene [12].

NTS cause a gastrointestinal infection which presents as inflammation manifested with diarrhea, nausea, vomiting, and headache [13]. The severity of infection varies depending on two factors; the serotype implicated and the health of the patient [14]. Infants, the elderly, and immunocompromised patients are more 
susceptible to NTS infections than healthy adults [14]. Although less common, some NTS actively invade intestinal epithelial cells using a type III secretion system (TTSS) to inject effector proteins into host cells, causing bacteremia [15].

\section{Mechanisms of pathogenesis}

A range of virulence genes contribute to Salmonella pathogenicity [16].Virulence determinants can be harbored on the chromosome, usually encoded on pathogenicity islands, or on plasmids and bacteriophages [9]. Moreover, cells of salmonella are surrounded by an outer membrane containing lipopolysaccharide (LPS) which is able to release lipid A endotoxin, potentially causing shock in the host [17]. Another component of virulence is the ability to synthesize enterobactin [18]. Enterobactin is a siderophore secreted by Salmonella allowing it to sequester iron from the host and use it for growth [19]. Salmonella actively invade intestinal epithelial cells using a type III secretion system (TTSS) to inject effector proteins into host cells [15]. Salmonella pathogenicity island 1 (SPI-1) encodes genes required in the invasion process, while SPI-2 encodes genes involved in intracellular survival and replication in phagocytic and non-phagocytic cells, and has a crucial role in systemic infection [20].

\section{Therapy for NTS infection}

Treatment for NTS infection does not usually require antimicrobials, because these do not reduce the duration or acuteness of gastroenteritis, and instead may result in extended carriage and appearance of resistant strains $[21,22]$. Nevertheless, antimicrobial therapy is considered for patients with severe diarrhea [6], and is commonly used for invasive salmonellosis or when individuals with immunodeficiency are affected [22].

\section{Salmonellosis in Algeria}

Contaminated poultry meat is one of the main sources of food-borne Salmonella in humans [23]. According to the Global Food-borne Infections Network (GFN) there is a lack of surveillance projects and initiatives in many developing countries which has led to an underreporting of Salmonella serovars in humans and from food sources [24]. Poor diagnostic capacity contributes to a lack of available data in developing countries; in contrast most data on Salmonella serovar distribution are available from industrialized countries [25].

In Algeria, there are few studies on the spread and distribution of serovars, or antimicrobial resistance in NTS. One reported superficial Salmonella contamination in ovine and bovine carcasses sampled from the slaughterhouse [26] but the remainder which include Salmonella tend to focus only on isolates from

Figure 1. Geographical location and distribution of reported NTS infection with a focus on North Algeria. Colors represent cities where NTS infection has been reported in the last 12 years.

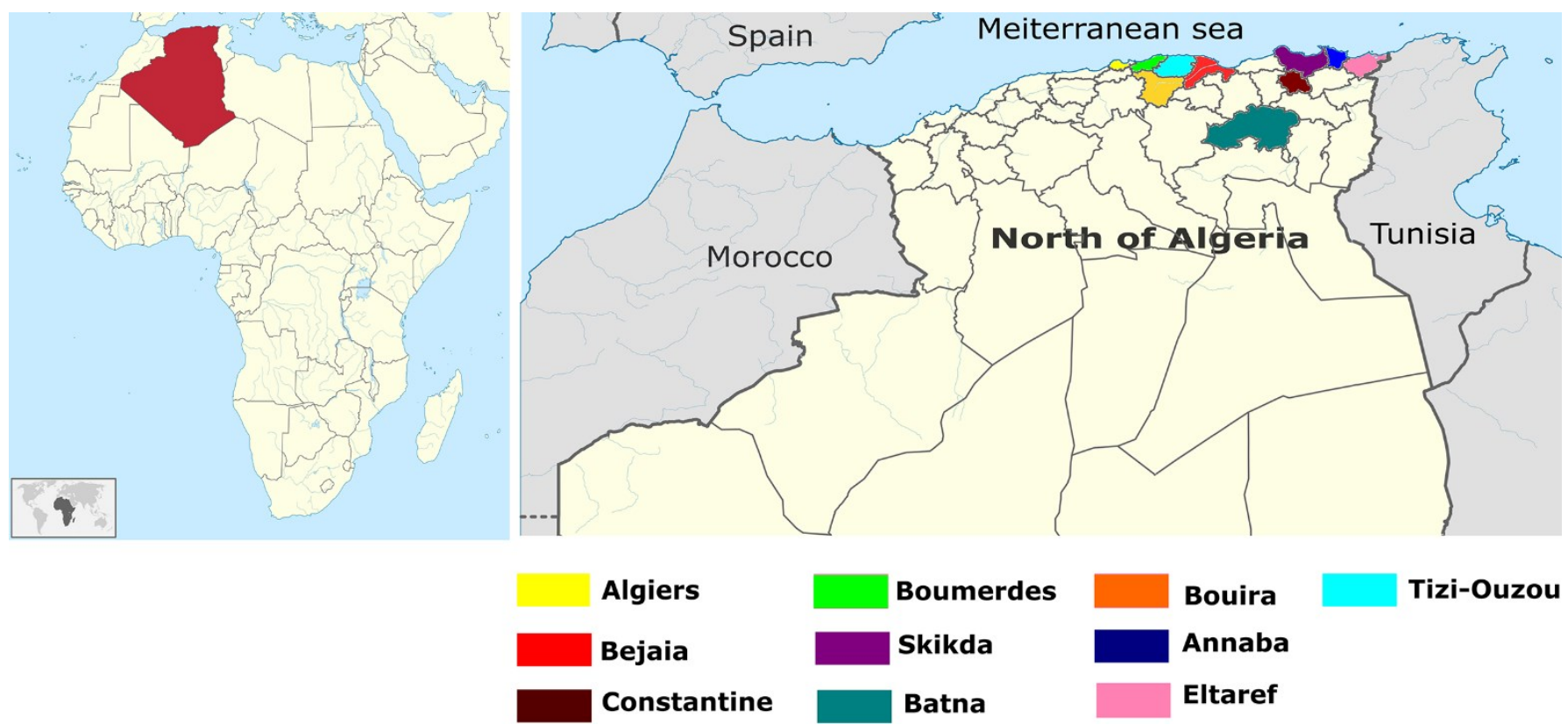


clinical or animal sources (essentially from broiler and/or laying-hen flocks) [10,27-29]. To date, these studies have been reported information from various cities in Algeria, including Algiers, Boumerdes, TiziOuzou, Bouira, Bejaia, Constantine, Batna, Annaba and El Taref (Figure 1) and are summarized below [10,2833].

One study from Algiers showed the detection of multiple Salmonella serovars contaminating a wide variety of raw meat and processed meat products, particularly from laying-hens [28,32] (Table 1). It is thought that this contamination probably takes place during meat processing at the retail level where more surfaces are exposed, as meat is deboned, cut into pieces, and minced [34]. Data from Batna, in eastern Algeria, identified the most common Salmonella serovars in broilers and laying breeding reproducers as $S$. Typhimurium and $S$. Livingstone, detected at a rate of $12 \%$ and $1.6 \%$ respectively in poultry feces, cloacal swabs and dusty surfaces. In addition, all the $S$. Typhimurium isolates were resistant to ampicillin, ticarcillin, chloramphenicol and trimethoprim/sulfamethoxazole. These findings indicate that the local poultry industry is not compliant with Algerian biosafety legislation [10]. In Constantine (eastern Algeria), another study highlighted the huge prevalence of NTS in the broiler production chain in this region. It showed that $37 \%$ of broiler farms and
$53 \%$ of slaughterhouses were positive for Salmonella upon inspection. Five serovars $(S$. Hadar, $S$. Virchow, $S$. Infantis, $S$. Albany and $S$. Carnac) were recovered from both types of site, with $S$. Heidelberg and $S$. Rissen only found on farms and $S$. Typhimurium, $S$. Enteritidis and $S$. Montevideo only found in slaughterhouses (Table 1). Among the 55 isolates of NTS, 51\% (39/55) were MDR and $80 \%(44 / 55)$ showed resistance to at least one antibiotic including streptomycin, tetracycline, nalidixic acid and ofloxacin (Table 2) [29].

A preliminary investigation was conducted for the prevalence of Salmonella contamination in laying-hen flocks in the neighboring regions of Annaba and El Taref (Figure 1). The most prevalent serovars isolated were $S$. Enteritidis, $S$. Kentucky, $S$. Hadar, $S$. Virchow, $S$. Heidelberg and $S$. Manhattan (Table 1) [28].

During 2007, a surveillance study was conducted on different poultry farms in four Algerian cities: TiziOuzou, Bouira, Bejaïa, and Boumerdes which identified thirteen serotypes among 100 isolates (Figure 1, Table 1) [35].

In Skikda, persistence of gastroenteritis infection within the poultry industry prompted an investigation for NTS in this sector in 2013. Of 27 poultry houses, $34 \%$ were found to be contaminated with Salmonella; the main NTS serotypes isolated were $S$. Kentucky and $S$. Heidelberg, then $S$. Enteritidis, $S$. Virginia and $S$. Newport (Table 1) [33].

Table 1. Serotypes of Non-Typhoidal Salmonella isolated in different cities in Algeria.

\begin{tabular}{|c|c|c|c|c|c|c|c|c|c|c|c|c|c|}
\hline \multirow{2}{*}{$\begin{array}{c}\text { Salmonella } \\
\text { serotypes }\end{array}$} & \multicolumn{10}{|c|}{ City of isolation } & \multirow{2}{*}{ Source of isolation } & \multirow{2}{*}{ Study } & \multirow{2}{*}{$\begin{array}{l}\text { Year of } \\
\text { Isolation }\end{array}$} \\
\hline & 1 & 2 & 3 & 4 & 5 & 6 & 7 & 8 & 9 & 10 & & & \\
\hline S. Anatum & + & & & + & & & & & & & Red meat, human & {$[26,27]$} & 2006-08 \\
\hline S. Altona & + & & & & & & & & & & Red meat & [27] & $2007-08$ \\
\hline S. Corvallis & + & & & & & & & & & & Red meat & {$[27]$} & 2007-08 \\
\hline S. Enteritidis & + & + & + & + & + & + & + & + & & + & Red meat, poultry, human & $\begin{array}{c}{[23,24,26-28} \\
30]\end{array}$ & 2005-09 \\
\hline S. Typhimurium & + & & + & + & & + & & & + & & Red meat, poultry, human & {$[11,26,27,30]$} & 2006-08 \\
\hline S. Livingstone & & & & & & & & & + & & Poultry & {$[11]$} & - \\
\hline S. Hadar & & & & + & & & + & + & & & Poultry & {$[23,24]$} & 2005-09 \\
\hline S. Virchow & & & & + & & & + & + & & & Poultry, human & {$[23,26]$} & 2008-09 \\
\hline S. Infantis & & & & + & & & & & & + & Poultry, human & {$[23,26,28]$} & $2008-13$ \\
\hline S. Albany & & + & + & + & + & + & & & & & Poultry & {$[11,30]$} & $2005-07$ \\
\hline S. Carnac & & & & + & & & & & & & Poultry & {$[11,30]$} & $2005-07$ \\
\hline S. Heidelberg & & + & + & + & + & + & + & + & & + & Poultry, human & {$[24,26,28,30]$} & $2005-07$ \\
\hline S. Rissen & & & & + & & & & & & & Poultry & [24] & $2005-07$ \\
\hline S. Montevideo & & & & + & & & & & & & Poultry & [24] & $2005-07$ \\
\hline S. Blockley & & & & + & & & & & & & Poultry & [24] & $2005-07$ \\
\hline S. Indiana & & & & + & & & & & & & Human & [26] & 2006-07 \\
\hline S. Kentucky & & & & + & & & & & & & Human & {$[26]$} & 2006-07 \\
\hline S. Senftenberg & & & & + & & & + & + & & + & Poultry, human & {$[23,26,28]$} & 2006-09 \\
\hline S. Manhattan & & & & & & & + & + & & & Poultry & [23] & 2008-09 \\
\hline S. Virginia & & & & & & & & & & + & Poultry & [28] & 2011-13 \\
\hline S. Newport & & & & & & & & & & + & Poultry & [28] & 2011-13 \\
\hline
\end{tabular}

$\mathbf{1}=$ Algiers. $\mathbf{2}=$ Boumerdes. $\mathbf{3}=$ Bouira. $\mathbf{4}=$ Contantine. $\mathbf{5}=$ Tizi-Ouzou. $\mathbf{6}=$ Bejaia. $\mathbf{7}=$ Annaba. $\mathbf{8}=$ Eltaref. $\mathbf{9}=$ Batna. 10= Skikda 
These studies conducted on NTS infection in Algeria, provide evidence for the presence of highly drug resistant serotypes. The serotypes identified from broilers and human clinical cases in Algeria are largely similar to those usually present in broilers worldwide, particularly in Europe and the USA, as well as Africa $[31,36,37]$. This highlights that NTS infection and antimicrobial resistance are matters of concern in Algeria that need to be dealt with in a more comprehensive manner.

As in many other developing countries, Algeria is facing a paucity of data on NTS infection, probably linked to poor diagnostic capacity and lack of epidemiological investigation. Effort should be focused upon the design and implementation of strategies for laboratory-based surveillance, which will in turn provide integrated data to public health authorities, allowing them to respond and intervene in NTS infection in an effective way.

\section{Antimicrobial resistant Salmonella across Africa}

Antimicrobials are used as common practice in modern food animal husbandry, for both therapeutic and prophylactic purposes [38]. Several studies suggest that antimicrobial resistance in NTS is promoted by the use of those antimicrobials in food animals [8,39-41]. The dissemination of Multi-Drug Resistant (MDR) Salmonella from animals to humans is a major adverse consequence for public health which is leading to a treatment failure in human infectious diseases [42]. Antibiotic resistance in NTS strains can be due to

Table 2. Antimicrobial resistance patterns of NTS in Algeria and some North African countries.

\begin{tabular}{|c|c|c|c|c|c|}
\hline $\begin{array}{l}\text { Country of } \\
\text { isolation }\end{array}$ & Serotypes & Antibiotic resistance profile & $\begin{array}{c}\text { Source of } \\
\text { isolation }\end{array}$ & Study & $\begin{array}{l}\text { Year of } \\
\text { Isolation }\end{array}$ \\
\hline \multirow[t]{17}{*}{ Algeria } & S. Agona & AMP. CEF. CTX. SXT. SU. GEN. STR & Human & [26] & $2006-07$ \\
\hline & S. Albany & NAL. OFX. STR & Human & {$[26]$} & 2006-07 \\
\hline & S. Enteritidis & AMP. CAZ. SU. TET & Human & {$[26]$} & 2006-07 \\
\hline & S. Hadar & AMP. NAL. OFX. STR. TET & Human & {$[26]$} & 2006-07 \\
\hline & S. Kentucky & AMP. CAZ, CEF. CTX. GEN. KAN. SU. SXT & Human & [26] & 2006-07 \\
\hline & S. Senftenberg & AMP. CAZ. CEF. CTX. GEM. KAN. NAL. STR. SU & Human & [26] & 2006-07 \\
\hline & S. Typhimurium & AMP. CHL. SU. STR. TET & Human & {$[26]$} & 2006-07 \\
\hline & S. Kentucky & AMP. CEF. STR. SXT. GEM. TET. NAL. OFX. ENR & Poultry & [23] & 2006-07 \\
\hline & S. Hadar & AMP. CEF. STR. TET. NAL & Poultry & [23] & 2006-07 \\
\hline & S. Albany & STR. NAL. OFX. ENR & Poultry & [24] & 2006-07 \\
\hline & S. Heilderberg & STR. NAL. OFX & Poultry & {$[24]$} & 2006-07 \\
\hline & S. Heilderberg & AMX. TIC. CTX. ATM. GEN. AK. SXT & Human & [28] & 2001-13 \\
\hline & S. Typhimurium & AMX. AMP. TIC. PIP. STR. NAL. SU. CHL. TET & Meat & {$[27]$} & 2007-08 \\
\hline & S. Anatum & STR. SU. TMP. SXT. F & Meat & [27] & 2007-08 \\
\hline & S. Altona & NA. $\mathrm{Su}$ & Meat & {$[27]$} & 2007-08 \\
\hline & S. Corvalis & SU & Meat & {$[27]$} & 2007-08 \\
\hline & S. Enteritidis & SU. F & Meat & {$[27]$} & 2007-08 \\
\hline \multirow[t]{8}{*}{ Tunisia } & S. Enteritidis & AMP. NAL. CAZ & Human & {$[41]$} & 2006-07 \\
\hline & S. Enteritidis & AMP & Human & [41] & 2006-07 \\
\hline & S. Enteritidis & $\mathrm{N}$ & Human & [41] & 2006-07 \\
\hline & S. Enteritidis & AMP, TE & Human & {$[41]$} & 2006-07 \\
\hline & S. Enteritidis & AMP, NA & Human & {$[41]$} & 2006-07 \\
\hline & S. Typhimurium & AMP. NAL. GEM & Human & [41] & 2006-07 \\
\hline & S. Zanzibar & AMP. TET. NAL. NEO. KAN & Human & [41] & 2006-07 \\
\hline & S. Muenster & CHL. TET. NEO & Human & [41] & 2006-07 \\
\hline \multirow[t]{4}{*}{ Egypt } & S. Typhimurium & $\begin{array}{l}\text { AMP. ERY. STR. TET. CO. SAM. SXT. CHL. NAL. GEM. } \\
\text { AMC }\end{array}$ & Human & {$[13]$} & 2014-15 \\
\hline & S. Rubislaw & AMP. ERY. STR. TET. SAM. SXT. CHL. NAL. GEM. AMC & Poultry & [13] & 2014-15 \\
\hline & S. Kiel & AMP. ERY. TET. AMC & Poultry & [13] & 2014-15 \\
\hline & S. Derby & ERY. STR. TET. AMC & Duck & [13] & 2014-15 \\
\hline Morocco & S. Enteritidis & AMP. SXT. NAL & Human & [39] & $2000-08$ \\
\hline \multirow[t]{2}{*}{ Senegal } & S. Kentucky & STR. KAN. TOB. GEN AMK. SU. TMP. TET & Human & {$[40]$} & 1999-09 \\
\hline & S. Typhilurium & STR. KAN. TOB. GEM. AMK. SU. TM & Human & [40] & 1999-09 \\
\hline
\end{tabular}

AK: Amikacin, AMP: Ampicillin, AMX: Amoxicillin, ATM: Aztreonam, CAZ: Ceftazidime, CEF: Cephalothin, CHL: Chloramphenicol, CO: Ceftriaxone, CTX: Cefotaxime, ENR: Enrofloxacin, ERY: Erythromycin, F: Furan, GEN: Gentamicin, KAN: Kanamycin, NAL: Nalidixic Acid, NEO: Neomycin, OFX: Ofloxacin, PIP: Piperacillin, SAM: Ampicillin-Sulbactam, STR: Streptomycin, SU: Sulfonamides, SXT: Trimethoprim-Sulfamethoxazole, TET: Tetracyclin, TIC: Ticarcillin, TOB: Tobramycin, TMP: Trimethoprim. 
genetic mutations or through the acquisition of resistance encoding genes on mobile elements [9]. Plasmids are typical carriers of determinants that confer resistance against conventional antibiotics such as ampicillin, chloramphenicol and tetracycline [43]. However, the chromosome can also harbor these determinants, e.g. on the multidrug resistance region of Salmonella Genomic Island 1 (SGI1) [9].

In Algeria, an increase in NTS has been observed among bacterial isolates in laboratories both clinically and in animals [30]. At present, the available data on NTS infection are not sufficient to understand the propagation of NTS through the food chain and into humans. One of the major consequences of such propagation could be resistance to antibiotics. More than $37 \%$ of broiler chain production were found to be infected with NTS in Constantine (Table 1) of which $51 \%$ were MDR [29]. A separate study showed $58 \%$ of 100 isolates demonstrated resistance to fluoroquinolones, particularly in $S$. Heidelberg [35]. It should be noted that an evaluation of risk factors showed that NTS infection in this region of Algeria is strongly linked to poor technical and hygiene practices [29].

The majority of antibiotic resistance determination in Algeria is based upon phenotypic characterization, and there is limited use of molecular biology to understand the spread of antibiotic resistance among food-borne bacteria. Multiple resistance types have been reported among different serotypes of NTS (Table 2 ), indicating the potential risk facing human health in the country through consuming food contaminated with resistant strains of NTS.

In Africa, the diversity of geography and low standards of living in many countries contribute to a lack of available data on NTS infection. Instead, estimations of the burden of drug resistant NTS infection must be made from isolated studies (Table 2).

In Morocco, during the period 2000 to 2008, outbreaks were reported with high levels of antibiotic resistant $S$. Enteritidis isolated from humans [44]. During the same period in Senegal, NTS serotypes isolated from patients showed an increase in resistance to amoxicillin from $0.9 \%$ to $11.1 \%$, and nalidixic acid from $0.9 \%$ to $26.7 \%$. Most of the NTS serotypes were $S$. Enteritidis, $S$. Typhimurium and $S$. Kentucky [45]. During 2006-2007 in Tunisia, several resistant NTS strains were isolated from human in different regions of the country, and most of them belonged to $S$. Enteritidis containing different patterns of resistance (Table 2) [46] . An Egyptian study conducted on Salmonella isolates from human and animals showed an increasing rate of antimicrobial resistance among NTS isolates between 2014 and 2015, in particular to erythromycin and tetracycline, and amoxicillin-clavulanic acid. This resistance was linked to over-use of antimicrobials in livestock [13]. In Kenya, among 342 NTS isolates, the prevalence of MDR strains reached $42 \%$ during 2003 [47]. A more recent study in 2014 from Ghana reported high levels of MDR Salmonella phenotypes ( $\mathrm{n}=$ $59 / 115,51.3 \%$ ) harboring resistance to ampicillin, cefuroxime, amoxicillin/clavulanic acid, chloramphenicol, cotrimoxazole and tetracycline [48].

In 2012, the European Food Safety Authority and European Centre for Disease Prevention and Control reported high levels of resistance to tetracyclines in NTS strains isolated in the EU, with a rate of $85 \%$ in poultry and $91 \%$ in swine. Similar rates of resistance were reported to sulfonamides and ampicillin. However, resistance to cephalosporins was low with maximum of $10 \%$ in both poultry and swine [37]. Reports from the National Antimicrobial Resistance Monitoring System (NARMS) in 2011 showed that NTS strains were isolated in the United States with high levels of resistance, particularly to penicillin, sulfonamides and tetracyclines in poultry, cattle and swine [49].

\section{Epidemiology of NTS}

As a result of consuming unsafe food, food-borne diseases have become a worldwide economic burden. Around 550 million individuals fall sick every year, including 220 million children under the age of 5 years [50]. Salmonella is one of the most reported causes of diarrheal disease globally [50]. In fact, the prevalence of Salmonella infection is higher than reported, because most infected people do not undergo copro-culture diagnosis [6].

Epidemiology related to NTS varies depending upon serovar, and its ability to cause gastrointestinal or invasive infection. With certain subtypes, $S$. Typhimurium is recognized as capable of causing bacteremia, whereas S. Heidelberg, $S$. Dublin, and $S$. Choleraesuis represent a significant potential to cause hospitalization, and even death. In comparison, serovar $S$. Newport was observed to cause fewer fatalities than $S$. Typhimurium [8].

Several outbreaks of food-borne infections of antibiotic resistant bacteria have been reported globally while individual epidemiology studies in moredeveloped African countries provide some basic insight until more data are available [51]. Such information is essential to understand the prevalence of multidrugresistant Salmonella strains [45]. In Algeria, there are 
very few epidemiological studies for NTS infection. During 2006 and 2007, a single epidemiological investigation was conducted on 100 strains of NTS from poultry and human clinical isolates in Constantine (Figure 1) in order to understand the contribution of avian NTS to human salmonellosis. Phenotypic and genotypic tests revealed a diversity among NTS serotypes (Table 2), but failed to confirm any association between the isolated serotypes even if they were collected in the same period of time [31].

In other parts of Africa, particular serovars are prevalent in specific regions, namely $S$. Concord in Ethiopia [52], $S$. Bovismorbificans in Malawi [53], $S$. Stanleyville and $S$. Dublin in Mali [54], and $S$. Isangi in South Africa [55]. In Kenya, an average of 166 per 100,000 children under five acquire an NTS infection every year $[56,57]$. In sub-Saharan Africa, a serious invasive form of NTS linked to $S$. Typhimurium sequence type 313 has emerged, and has become a leading public health issue in this region. This invasive $S$. Typhimurium had an estimated mortality rate of 20 $25 \%$ in children and up to $50 \%$ in adults [58].

Food-borne Salmonella is the largest health burden of all bacterial pathogens in the US [59]. During 2014, a total of 19,057 laboratory-confirmed cases of foodborne infections were identified. Salmonella was linked to 7439 of these cases, in which 2144 persons were hospitalized, and among them 32 patients died [60]. The most commonly detected serovars of Salmonella in humans include $S$. Enteritidis and $S$. Typhimurium, followed by $S$. Newport, $S$. Javiana, and Salmonella with the antigenic formula 4, [5], 12:i:- [61].

Although developed countries have a better awareness among food handlers and optimized surveillance programs, NTS infection has been detected and considered responsible for patient morbidity and mortality for decades. For developing countries, the situation worsened by the limited sources currently available. Due to robust globalization and scanty Salmonella surveillance programs in most developing countries, the world is now dealing with a new challenge from Salmonella enterica spp. that are potentially multidrug resistant [38] and may spread all over the food chain $[38,62]$. In addition, massive human migration from African countries and an increase in food trade between developing and developed countries may play a role in spreading such isolates all over the world.

\section{Conclusions}

NTS infection is a global issue with a higher prevalence and burden in developing countries such as
Algeria. A strong foundation of reliable research data is needed to effectively describe NTS infection and trace public health consequences among the Algerian population. To achieve this aim, detailed national epidemiological and microbiological studies should be set up in order to evaluate the prevalence of NTS in every food of animal origin, determine which serovars are in circulation, and better understand the relationship between food production and outbreaks of human salmonellosis in Algeria.

\section{References}

1. Schlundt J, Toyofuku H, Jansen J, Herbst S (2004) Emerging food-borne zoonoses. Rev Sci Tech Oie 23: 513-534.

2. Bell C andKyriakides A (2002) Salmonella: a practical approach to the organism and its control in foods, Oxford: John Wiley \& Sons $336 \mathrm{p}$

3. Brenner F, Villar R, Angulo F, Tauxe R, Swaminathan B (2000) Salmonella nomenclature. J Clin Microbiol 38: 24652467.

4. Porwollik S (2011) Salmonella: from genome to function, Norfolk UK: Caister Academic Press 300 p.

5. Gal-Mor O, Boyle E C, Grassl G A (2014) Same species, different diseases: how and why typhoidal and non-typhoidal Salmonella enterica serovars differ. Front Microbiol 5: 391.

6. Roy SL (2011) Infectious diseases related to travel. CDC Health Information for International Travel 2012: The Yellow Book. Oxford University Press 6:134

7. Food and Drug Administration/ Center for Food Safety and Applied Nutrition (2008) Food Safety A to Z Reference GuideSalmonella. Available: https://www.fda.gov/downloads/food/foodscienceresearch/too 1smaterials/ucm430363.pdf. Accessed 01 June 2017.

8. Crump JA, Medalla FM, Joyce KW, Krueger AL, Hoekstra RM, Whichard JM, Barzilay EJ, Group EIPNW (2011) Antimicrobial resistance among invasive nontyphoidal Salmonella enterica in the United States, national antimicrobial resistance monitoring system, 1996-2007. Antimicrob Agents Chemother 28: 0066-4804.

9. Fluit AC (2005) Towards more virulent and antibiotic-resistant Salmonella? FEMS Immunol Med Microbiol 43: 1-11.

10. Ayachi A, Alloui N, Bennoune O, Kassah-Laouar A (2010) Survey of Salmonella serovars in broilers and laying breeding reproducers in East Algeria. J Infect Dev Ctries 4: 103-106.

11. Ayachi A, Alloui N, Bennoune O, Yakhlef G, Amiour W D, Bouzdi S, Zoughlache K D, Boudjellal K, Abdessemed H (2009) Antibacterial activity of some fruits; berries and medicinal herb extracts against poultry strains of Salmonella. Am Eurasian J Agric Environ Sci 6: 12-15.

12. Rhen M, Maskell D, Mastroeni P, Threlfall J (2007) Salmonella: molecular biology and pathogenesis. Horizon Bioscience $194 \mathrm{p}$.

13. Gharieb RM, Tartor YH, Khedr MH (2015) Non-Typhoidal Salmonella in poultry meat and diarrhoeic patients: prevalence, antibiogram, virulotyping, molecular detection and sequencing of class I integrons in multidrug resistant strains. Gut Pathog 7: 34.

14. Eng SK, Pusparajah P, Ab Mutalib NS, Ser HL, Chan KG, Lee LH (2015) Salmonella: A review on pathogenesis, epidemiology and antibiotic resistance. Front Life Sci 8: 284293. 
15. Galán J E, Wolf-Watz H (2006) Protein delivery into eukaryotic cells by type III secretion machines. Nature 444: 567-573.

16. Marcus SL, Brumell JH, Pfeifer CG, Finlay BB (2000) Salmonella pathogenicity islands: big virulence in small packages. Microb Infect 2: 145-156.

17. Shahin RD, Engberg I, Hagberg L, Eden CS (1987) Neutrophil recruitment and bacterial clearance correlated with LPS responsiveness in local gram-negative infection. J Immunol. 138: 3475-3480.

18. Pollack JR, Neilands J (1970) Enterobactin, an iron transport compound from Salmonella typhimurium. Biochem Biophys Res Commun38: 989-992.

19. Nagy TA, Moreland SM, Andrews-Polymenis H, Detweiler CS (2013) The ferric enterobactin transporter Fep is required for persistent Salmonella enterica serovar typhimurium infection. Infect Immun 81: 4063-4070.

20. Abrahams GL, Hensel M (2006) Manipulating cellular transport and immune responses: dynamic interactions between intracellular Salmonella enterica and its host cells. Cell Microbiol 8: 728-737.

21. Su L, Chiu C (2007) Salmonella: clinical importance and evolution of nomenclature. Chang Gung Med J 30: 210.

22. Yan SS, Pendrak ML, Abela-Ridder B, Punderson JW, Fedorko DP, Foley SL (2004) An overview of Salmonella typing: public health perspectives. Clin App Immunol Rev 4: 189-204.

23. Butaye P, Michael G B, Schwarz S, Barrett T J, Brisabois A, White D G (2006) The clonal spread of multidrug-resistant non-typhi Salmonella serotypes. Microb Infect 8: 1891-1897.

24. Galanis E, Wong DMLF, Patrick ME, Binsztein N, Cieslik A, Chalermchaikit T, Aidara-Kane A, Ellis A, Angulo FJ, Wegener HC (2006) Web-based surveillance and global Salmonella distribution, 2000-2002. Emerg Infect Diseases 12: 381 .

25. Wagenaar J, Hendriksen R, Carrique-Mas J (2013) Practical considerations of surveillance of Salmonella serovars other than Enteritidis and Typhimurium. Rev Sci Tech 32: 509-519.

26. Nouichi S, Hamdi TM (2009) Superficial bacterial contamination of ovine and bovine carcasses at El-Harrach slaughterhouse (Algeria). Eur J Sci Res. 38: 474-485.

27. Boudilmi B, Chalabi N (1997) Avian salmonellosis in Algeria. Public Health Impact. International Symposium on Salmonella and Salmonellosis (I3S) Proceedings, Ploufragan, France 365-366. [Article in French].

28. Bouzidi N, Aoun L, Zeghdoudi M, Bensouilah M, Elgroud R, Oucief I, Granier SA, Brisabois A, Desquilbet L, Millemann Y (2012) Salmonella contamination of laying-hen flocks in two regions of Algeria Food Res Int 45: 897-904.

29. Elgroud R, Zerdoumi F, Benazzouz M, BouzitounaBentchouala C, Granier S, Frémy S, Brisabois A, Dufour B, Millemann Y (2009) Characteristics of Salmonella contamination of broilers and slaughterhouses in the region of Constantine (Algeria). Zoonoses Public Health 56: 84-93.

30. Aboun A, Benelmouffok A, Bougueddour R, Taril A, Rezkallah M, Selatnia L (2000) Avian salmonellosis diagnosed at the Pasteur Institute of Algeria from 1988 to 2002: serotypes encountered, their antibiotic resistance and regulatory aspects. Arch Inst Pasteur Alger 2003: 93-114. [Article in French.]

31. Elgroud R, Granier SA, Marault M, Kerouanton A, Lezzar A, Bouzitouna-Bentchouala C, Brisabois A, Millemann Y (2015) Contribution of avian Salmonella enterica isolates to human salmonellosis cases in Constantine (Algeria). BioMed Res Int 2015: 2314-6133.

32. Mezali L, Hamdi TM (2012) Prevalence and antimicrobial resistance of Salmonella isolated from meat and meat products in Algiers (Algeria). Foodborne Pathog Dis 9: 522-529.

33. Djeffal S, Bakour S, Mamache B, Elgroud R, Agabou A, Chabou S, Hireche S, Bouaziz O, Rahal K, Rolain J-M (2017) Prevalence and clonal relationship of ESBL-producing Salmonella strains from humans and poultry in northeastern Algeria. BMC Vet Res 13: 132.

34. Ejeta G, Molla B, Alemayehu D, Muckle A (2004) Salmonella serotypes isolated from minced meat beef, mutton and pork in Addis Ababa, Ethiopia. Rev Med Vet 155: 547-551.

35. Bounar-Kechih S, Hamdi T, Mezali L, Assaous F, Rahal K (2012) Antimicrobial resistance of 100 Salmonella strains isolated from Gallus gallus in 4 wilayas of Algeria. Poult Sci 91: 1179-1185.

36. Hendriksen RS, Vieira AR, Karlsmose S, Lo Fo Wong DM, Jensen AB, Wegener H C, Aarestrup FM (2011) Global monitoring of Salmonella serovar distribution from the World Health Organization Global Foodborne Infections Network Country Data Bank: results of quality assured laboratories from 2001 to 2007. Foodborne Pathog Dis 8: 887-900.

37. Eurosurveillance Editorial Team (2012) The European Union summary report on trends and sources of zoonoses, zoonotic agents and food-borne outbreaks in 2010. Eurosurveillance 1560-7917: 17.

38. Aarestrup F M, Hendriksen R S, Lockett J, Gay K, Teates K, McDermott P F, White D G, Hasman H, Sørensen G, Bangtrakulnonth A (2007) International spread of multidrugresistant Salmonella Schwarzengrund in food products. Emerg Infect Diseases 13: 726.

39. Angulo FJ, Johnson KR, Tauxe RV, Cohen ML (2000) Origins and consequences of antimicrobial-resistant nontyphoidal Salmonella: implications for the use of fluoroquinolones in food animals. Microb Drug Resist 6: 77-83.

40. Dutil L, Irwin R, Finley R, Ng LK, Avery B, Boerlin P, Bourgault AM, Cole L, Daignault D, Desruisseau A (2010) Ceftiofur resistance in Salmonella enterica serovar Heidelberg from chicken meat and humans, Canada. Emerg Infect Diseases 16: 48.

41. Gupta A, Fontana J, Crowe C, Bolstorff B, Stout A, Van Duyne S, Hoekstra MP, Whichard JM, Barrett TJ, Group NARMSPW (2003) Emergence of multidrug-resistant Salmonella enterica serotype Newport infections resistant to expanded-spectrum cephalosporins in the United States. J Infect Dis 188: 17071716.

42. Jordan D, Chin J C, Fahy V, Barton M, Smith M, Trott D (2009) Antimicrobial use in the Australian pig industry: results of a national survey. Aust Vet J 87: 222-229.

43. Guerra B, Soto SM, Argüelles JM, Mendoza MC (2001) Multidrug resistance is mediated by large plasmids carrying a class 1 integron in the emergent Salmonella enterica serotype [4, 5, 12: i:- ]. Antimicrob Agents Chemother 45: 1305-1308.

44. Ohmani F, Khedid K, Britel S, Qasmaoui A, Charof R, FilaliMaltouf A, El Aouad R (2010) Antimicrobial resistance in Salmonella enterica serovar Enteritidis in Morocco. J Infect Dev Ctries 4: 804-809 https://doi.org/10.3855/jidc.806.

45. Harrois D, Breurec S, Seck A, Delauné A, Le Hello S, Pardos de la Gándara M, Sontag L, Perrier-Gros-Claude J D, Sire J M, Garin B (2014) Prevalence and characterization of extendedspectrum $\beta$-lactamase-producing clinical Salmonella enterica 
isolates in Dakar, Senegal, from 1999 to 2009. Clin Microbiol Infect 20: 1469-0691.

46. Abbassi-Ghozzi I, Jaouani A, Aissa R, Martinez-Urtaza J, Boudabous A, Gtari M (2011) Antimicrobial resistance and molecular analysis of non-typhoidal Salmonella isolates from human in Tunisia. Pathol Biol 59: 207-212.

47. Kariuki S, Revathi G, Kariuki N, Muyodi J, Mwituria J, Munyalo A, Kagendo D, Murungi L, Hart CA (2005) Increasing prevalence of multidrug-resistant non-typhoidal salmonellae, Kenya, 1994-2003. Int J Antimicrob Agents 25: 38-43.

48. Labi A-K, Obeng-Nkrumah N, Addison NO, Donkor ES (2014) Salmonella blood stream infections in a tertiary care setting in Ghana. BMC Infect Dis 14: 3857.

49. Food and Drug Administration (2011) National Antimicrobial Resistance Monitoring System. 2011 Executive Report. Available:

https://www.fda.gov/downloads/AnimalVeterinary/SafetyHea 1th/AntimicrobialResistance/NationalAntimicrobialResistance MonitoringSystem/UCM407962.pdf. Accessed 01 June 2017.

50. World Health Organization (2016) updates fact sheet on nontyphoidal Salmonella. Available

51. Enwere G, Biney E, Cheung Y, Zaman SM, Okoko B, Oluwalana C, Vaughan A, Greenwood B, Adegbola R, Cutts FT (2006) Epidemiologic and clinical characteristics of community-acquired invasive bacterial infections in children aged 2-29 months in The Gambia. Pediatr Infect Dis J 25: 700705.

52. Beyene G, Nair S, Asrat D, Mengistu Y, Engers H, Wain J (2011) Multidrug resistant Salmonella Concord is a major cause of salmonellosis in children in Ethiopia. J Infect Dev Ctries 5: 23-33 https://doi.org/10.3855/jidc.906.

53. Bronowski C, Fookes MC, Gilderthorp R, Ashelford KE, Harris SR, Phiri A, Hall N, Gordon MA, Wain J, Hart CA (2013) Genomic characterisation of invasive non-typhoidal Salmonella enterica Subspecies enterica Serovar Bovismorbificans isolates from Malawi. PLoS Negl Trop Dis 7: e2557.

54. Tennant SM, Diallo S, Levy H, Livio S, Sow SO, Tapia M, Fields PI, Mikoleit M, Tamboura B, Kotloff KL (2010) Identification by PCR of non-typhoidal Salmonella enterica serovars associated with invasive infections among febrile patients in Mali. PLoS Negl Trop Dis 4: e621.

55. Wadula J, Von Gottberg A, Kilner D, De Jong G, Cohen C, Khoosal M, Keddy K, Crewe-Brown H (2006) Nosocomial outbreak of extended-spectrum $\beta$-lactamase-producing
Salmonella Isangi in pediatric wards. Pediatr Infect Dis J 25: 843-844.

56. Berkley JA, Lowe BS, Mwangi I, Williams T, Bauni E, Mwarumba S, Ngetsa C, Slack MP, Njenga S, Hart CA (2005) Bacteremia among children admitted to a rural hospital in Kenya. N Engl J Med 352: 39-47.

57. Oundo J, Muli F, Kariuki S, Waiyaki P, Iijima Y, Berkley J, Kokwaro G, Ngetsa C, Mwarumba S, Torto R (2002) Nontyphi salmonella in children with severe malaria. East Afr Med J 79: 633-639.

58. Kingsley RA, Msefula CL, Thomson NR, Kariuki S, Holt KE, Gordon MA, Harris D, Clarke L, Whitehead S, Sangal V (2009) Epidemic multiple drug resistant Salmonella Typhimurium causing invasive disease in sub-Saharan Africa have a distinct genotype. Genome Res19: 2279-2287.

59. Scallan E, Hoekstra RM, Angulo FJ, Tauxe RV, Widdowson MA, Roy SL, Jones J L, Griffin PM (2011) Foodborne illness acquired in the United States major pathogens. Emerg Infect Dis 17: 1080-6059.

60. Atlanta, Georgia: U.S. Department of Health and Human Services, CDC (2014) Foodborne Diseases Active Surveillance Network (FoodNet): FoodNet Surveillance Report for 2014 (Final Report). Available: https://www.cdc.gov/foodnet/pdfs/2014-foodnet-surveillancereport.pdf. Accessed 01 June 2017.

61. Atlanta, Georgia: U.S. Department of Health and Human Services, CDC (2015) Foodborne Diseases Active Surveillance Network (FoodNet): FoodNet Surveillance Report for 2012 (Final Report). Available: https://www.cdc.gov/foodnet/pdfs/2012_annual_report_508c. pdf Accessed 01 June 2017.

62. Clark G, Gangarosa A KJ, Thompson M (1973) Epidemiology of an international outbreak of Salmonella agona. The Lancet. 302: 490-493.

\section{Corresponding author}

Bilal Djeghout

Laboratory of Microbiology and Virology, Department of

Biomedical Sciences, University of Sassari, V. le San Pietro 43/B, 07100 Sassari, Italy.

Phone: +393463083681

Email: bilal.djeghout@gmail.com

Conflict of interests: No conflict of interests is declared. 